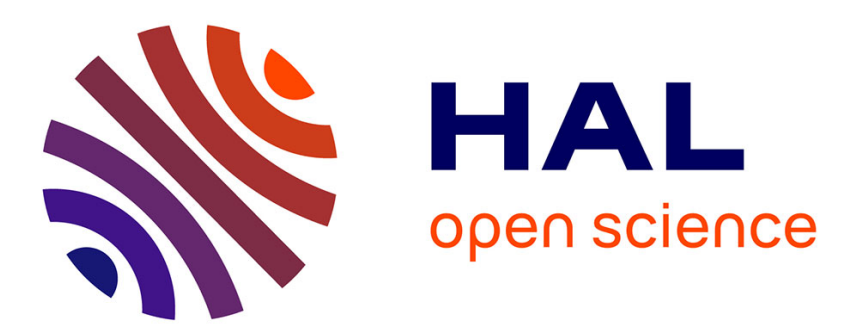

\title{
A sharp incisor tool for predator house mice back to the wild
}

Sabrina Renaud, Claire Delépine, Ronan Ledevin, Benoît Pisanu, Jean-pierre

Quéré, Emilie A Hardouin

\section{> To cite this version:}

Sabrina Renaud, Claire Delépine, Ronan Ledevin, Benoît Pisanu, Jean-pierre Quéré, et al.. A sharp incisor tool for predator house mice back to the wild. Journal of Zoological Systematics and Evolutionary Research, 2019, 57 (4), pp.989-999. 10.1111/jzs.12292 . hal-02336353

\section{HAL Id: hal-02336353 \\ https://hal.science/hal-02336353}

Submitted on 21 Nov 2020

HAL is a multi-disciplinary open access archive for the deposit and dissemination of scientific research documents, whether they are published or not. The documents may come from teaching and research institutions in France or abroad, or from public or private research centers.
L'archive ouverte pluridisciplinaire HAL, est destinée au dépôt et à la diffusion de documents scientifiques de niveau recherche, publiés ou non, émanant des établissements d'enseignement et de recherche français ou étrangers, des laboratoires publics ou privés. 
1

2

3

4

5

$6 \quad{ }^{1}$ Laboratoire de Biométrie et Biologie Evolutive, UMR5558 CNRS Université Lyon 1, Campus de la 7

8

9

\section{A sharp incisor tool for predator house mice back to the wild}

SABRINA RENAUD ${ }^{1 *}$, CLAIRE DELEPINE ${ }^{1}$, RONAN LEDEVIN ${ }^{2}$, BENOIT PISANU ${ }^{3}$, JEAN-PIERRE QUERE ${ }^{4}$, EMILIE A. HARDOUIN ${ }^{5}$

Doua, 69100 Villeurbanne, France

${ }^{2}$ UMR5199 PACEA, Université de Bordeaux, Allée Geoffroy Saint Hilaire (Bat. B8), 33615 PESSAC,

France

${ }^{3}$ Centre d'Ecologie et des Sciences de la Conservation, UMR 7204, Sorbonne Universités, Muséum National d'Histoire Naturelle, CNRS, Université Pierre et Marie Curie, 61 rue Buffon, F-75005 Paris, France

${ }^{4}$ Centre de Biologie et Gestion des Populations (INRA / IRD / Cirad / Montpellier SupAgro), Campus international de Baillarguet, CS 30016, F-34988, Montferrier-sur-Lez Cedex, France

${ }^{5}$ Department of Life and Environmental Sciences, Faculty of Sciences and Technology, Bournemouth University, Christchurch House, Talbot Campus, Poole, Dorset, BH12 5BB, UK

Running title: Incisor shape of predator house mice

* Corresponding author:

Sabrina Renaud

E-mail: Sabrina.Renaud@univ-lyon1.fr

\section{Keywords}

geometric morphometrics, Mus musculus domesticus, adaptation, biting, functional morphology 


\section{Abstract}

The house mouse (Mus musculus domesticus), as a successful invasive species worldwide, has to forage a variety of resources. Sub-Antarctic mice display among the most notable diet shift from the usual omnivorous-granivorous diet, relying on a larger proportion of terrestrial animal prey. In agreement, a recent study of their mandible morphology evidenced an evolution of their mandible shape to optimize incisor biting, and hence seize preys. Here, the incisors themselves are the focus of a morphometric analysis combined with a 3D study of their internal structure, aiming at a comparison between a Sub-Antarctic population (Guillou island, Kerguelen archipelago) with a range of Western European continental, commensal mice. The predatory foraging behavior of Guillou mice was indeed associated with a sharper bevel of the lower incisor, which appears as an efficient morphology for piercing prey. The incisor of these mice also display a reduced pulp cavity, suggesting slower eruption counter-balancing a reduced abrasion on such soft food material. The dynamics of the ever-growing incisor may thus allow adaptive incisor sculpting and participate to the success of mice in foraging diverse resources. 


\section{Introduction}

Adaptations to successfully gather and process food are crucial for insuring survival and resources for any function of an organism. They can involve many facets including digestive tract and behavior, and in mammals, they further rely on a sophisticated dentition. Premolars and molars have evolved complex morphologies for matching functional requirements related to various diets, and are therefore the focus of many studies including morphofunctional and developmental aspects [e.g. (Evans et al., 2007; Jernvall et al., 1996; Popowics \& Fortelius, 1997)]. Incisors, in contrast, deserved little interest, possibly due to their simple geometry, despite the fact that they often represent the first tool to be in contact with food particles. In rodents and lagomorphs, incisors are ever-growing, with a high growth rate that counterbalances continuous wear. Ever-growing incisors are the most striking characteristic of the rodent order and they were probably a key component of the extensive evolutionary radiation of rodents (Fabre et al., 2012; Steppan \& Schenk, 2017), associated with the versatility of their feeding habits (Landry, 1970; Martin et al., 2016). How the dynamics of eruption varies through the animal's life, and in response to diet, has been investigated (Harari et al., 2005; Klevezal \& Shchepotkin, 2012; Taylor \& Butcher, 1951). Differences in terms of relative curvature, coverage by the enamel and cross-sectional profile have been demonstrated between species of murine rodents, with a possible link with habitats (Millien-Parra, 2000). Adaptations in terms of curvature of the incisors have been further reported in chisel tooth digging rodents, in which functional loads on the skull and incisors are extremely high (Samuels \& Van Valkenburgh, 2009) and in carnivorous rodents, in which low incisor curvature may improve the function of stabbing preys (Fabre et al., 2017; Rowe et al., 2016). The geometry of the incisor's bevel, which constitutes its cutting edge, may be of functional relevance for facing different diets but its role has never been addressed directly in wild populations, especially at the intraspecific level. However, the incisor evergrowing dynamics that can be modulated through the intensity of wear (Meredith et al., 2015; Müller et al., 2014; Taylor \& Butcher, 1951) may allow a rapid adjustment to varying food requirements.

Being commensal, the house mouse (Mus musculus domesticus Schwarz and Schwarz 1943) followed the movement of people around the world, making it a highly successful global invader (Lowe et al., 2000). It colonized even remote and inhospitable environments, such as Sub-Antarctic islands. On these remote islands, the mice face conditions widely departing from their usual commensal habits. Mice shifted their diet from their usual omnivorous-granivorous diet to a larger proportion of terrestrial animal prey, mostly above ground and litter macroinvertebrates (Le Roux et al., 2002; van Aarde \& Jackson, 2007). Such diet shifts triggered convergent evolution of mandible geometry in various populations of Sub-Antarctic mice, all displaying an increased biomechanical functional performance for incisor biting, constituting an adaptation to catch prey more efficiently (Renaud et 
al., 2018). If the incisor itself displayed adaptive change to increase prey catching was not investigated.

The small Guillou Island $\left(1.45 \mathrm{~km}^{2}\right)$ is one of the Sub-Antarctic islands where house mice built successful feral populations by relying on a large component of invertebrates in their diet (Le Roux et al., 2002). It is part of the Sub-Antarctic Kerguelen Archipelago, situated in the Indian Ocean about $4000 \mathrm{~km}$ away from the African and Australian coasts. Mice were introduced on the archipelago during the $19^{\text {th }}$ century (Kidder, 1876). Functional response to the diet shift had thus to evolve in less than two centuries. This evolution occurred in isolation, even from the rest of the archipelago, since Guillou mice all display the same mitochondrial haplotype, and evidence a strong differentiation from mice from other Kerguelen islands (Hardouin et al., 2010). Furthermore, the island experienced in the last two decades a cortege of human-driven modifications: rabbit (Oryctolagus cuniculus) eradication by poisoning in 1994 (Chapuis et al., 2001); regression of the native vegetation cover against invasive plants (Chapuis et al., 2004) and increasing summer drought (Lebouvier et al., 2011) decreasing earthworms availability in the litter, both as a consequence of climate change; regression of most native insects because of the spread of an invasive carabid predator (Merizodus soledadenus) over the last 15 years (Laparie et al., 2010). All may have changed access and composition of the resources available to mice, as exemplified by a change in mandible shape and an increase in its mineralization from 1993 to 2009, suggesting a higher investment in this trait and/or increased food quality (Renaud, Gomes Rodrigues, et al., 2015).

In the present study, the incisor morphology in the house mouse population inhabiting the Guillou Island was investigated. First, the shape of the erupted part of the upper and lower incisors was quantified using 2D geometric morphometrics. Guillou mice were compared to several populations of continental Europe, documenting the usual commensal habitat where mice display an omnivorous-granivorous diet. Four sampling years on Guillou, from 1993 to 2009, allowed documenting the morphology of Guillou mice and its change through time. The objective was to assess if incisor morphology differed between Guillou and continental mice, in relation with the more predatory behavior of the former; and if it varied through years in Guillou, in response to the cohort of human-driven environmental changes. In case of an adaptive response, sharper incisor tips were expected in the predatory Guillou mice. On a subset of mice, 3D imaging of the incisors further allowed to identify changes in the internal structure of the tooth, providing an insight into the developmental processes involved in the incisor shape variations.

\section{Material and Methods}




\section{Material}

The sampling for Guillou Island included mice trapped on four years covering a 16 years' interval (1993, 2001, 2008 and 2009) (Chapuis et al., 2001; Renaud, Gomes Rodrigues, et al., 2015). Four Western European populations were used for comparison: Cologne-Bonn (Germany), Gardouch (South-Western France), Tourch (Brittany, France) (Renaud et al., 2017) and Balan (nearby Lyon, France) (Fig. S1 and Table S1 in the Supporting Informations).

Almost all mice considered were sub-adults and adults, the criteria being the full eruption of the third molars that occurs at weaning; for some mice in Balan, the eruption was ongoing. Sexual dimorphism was not evidenced in continental nor in Guillou populations (Renaud et al., 2013; Renaud et al., 2017). Furthermore, sexual dimorphism in incisor size has been shown to be very limited in other species of rodents (Millien-Parra, 2000). Hence, males and females were pooled for further analyses. For all mice except those from Cologne-Bonn, body weight data were available. Mandible area provided a further proxy of body size available for all populations (Renaud, Gomes Rodrigues, et al., 2015; Renaud et al., 2017).

\section{Morphometric analysis of the incisors}

The shape of the lower incisor was quantified based on 2D pictures of the mandible in labial view, using a set of four landmarks and 8 sliding semi-landmarks (Fig. 1A) describing the erupted part of the tooth. The upper incisor was quantified based on 2D pictures of the skull in lateral view, using a set of three landmarks and 16 semi-landmarks. A total of 267 lower incisors and 209 upper incisors were included in the final data set. For estimating measurement error, the population from CologneBonn was measured twice at several weeks of interval by the same operator (CD).

The configurations of landmarks and semi-landmarks were superimposed using a generalized Procrustes analysis (GPA) standardizing size, position and orientation while retaining the geometric relationships between specimens (Rohlf \& Slice, 1990). During the superimposition, semi-landmarks were allowed sliding along their tangent vectors until their positions minimize the shape difference between specimens, the criterion being the bending energy. A Principal Component Analysis (PCA) on the variance-covariance matrix of the aligned coordinates was used to summarized the shape variance. Shape differences between groups (localities, and for Guillou the different years of trapping) were tested using a permanova (non-parametric multivariate analysis of variance based on 9999 permutations) and associated pairwise post-hoc tests, using the PC axes explaining more than $5 \%$ of total variance. The pattern of differentiation between groups was further investigated using 
142 Canonical Variate Analyses (CVA) on the aligned coordinates. This method aims at separating groups

143 by looking for linear combinations of variables that maximize the between-group to within-group

144 variance ratio. By standardizing within-group variance, it is efficient for evidencing relationships

145 between groups even in the case of important anisotropic within-group variance, as may be the case 146 when within-group allometry is important (Renaud, Dufour, et al., 2015).

147 Differences in incisor size, estimated by the centroid size (CS: square root of the sum of squared 148 distances from the landmarks and semi-landmarks to the centroid), and its relationship with body 149 weight (BW) and mandible area were investigated using linear models. The continental vs Guillou 150 origin of the mice was included as a factor in some models and the associated size and shape 151 differences were assessed using t-tests. Allometric shape variations were assessed using linear 152 models between size and the first axis of the PCA, and in a multivariate way, using Procrustes ANOVA 153 comparing size and the aligned coordinates (tests based on 9999 permutations). A visualization of 154 the allometric pattern was provided using the regression score (Adams \& Otarola-Castillo, 2013).

155 For assessing measurement error, separate Procrustes superimpositions focused on datasets 156 including only the two sessions of measurements of the Cologne-Bonn (CB) population were 157 performed. The difference between the two sessions were assessed using t-tests for centroid size, 158 and Procrustes ANOVA for the aligned coordinates.

159 Procrustes superimposition, PCA on the aligned coordinates and Procrustes ANOVA were performed 160 using the R package geomorph (Adams \& Otarola-Castillo, 2013). Canonical Variate Analyses were 161 computed using the package Morpho (Schlager, 2017). Permanova were performed using Past 3 162 (Hammer et al., 2001). The data are available as Supplementary Data (Supp. Data 1 and 2 for the 163 lower and upper incisors respectively).

A subset of Guillou (4 from 1993 and 4 from 2009) and continental mice (4 from Cologne-Bonn, CB) were CT-scanned at a cubic voxel resolution of $18 \mu \mathrm{m}$ using a RX-Skyscan 1076 device at the Platform Montpellier RIO Imaging. The protocol used during the scanning and the reconstruction of the radiographic data (software NRecon v1.6.6.0) was identical for all specimens, allowing direct comparisons of the data (Renaud, Gomes Rodrigues, et al., 2015). Reconstructed data consist of a stack of cross-sectional greyscale images, the grey value (GV) in each pixel being associated to a density value. The higher the grey level, the higher is the density in the concerned pixel. Based on these scans, the structure of the lower incisors was investigated. 
First, the scans were reoriented using Avizo in order to get a cross-section of the lower incisor between the basis of the bevel and the mandibular bone (Fig. 1B). These slices were transformed in 8-bits grey levels (GV ranging from 1 to 256) and analyzed using the image analyzing software Optimas 6.5. Area of the cross-section and its mean and minimal grey values were estimated for each incisor. Differences between continental and Guillou mice were tested using t-tests.

Regarding 3D volumes, isosurfaces were constructed based on several thresholds in order to delineate the mandible itself (right hemi-mandible including bone and teeth), the dentine and the enamel of each lower incisor. The mandible was reconstructed by including all material with a grey value $>9000$. The dentine surface of the lower incisor was estimated by including all material with $20000<\mathrm{GV}<40000$; connections with the mandibular bone were manually removed. The enamel surface was estimated by including all material with GV $>40000$.

For each object (mandible, dentine and enamel of the lower incisor), the volume and mean GV was calculated. Based on a visualization of the mandible, dentine and enamel in lingual view, a set of five landmarks was used to assess geometric differences of the internal structure related to the mandibular bone (Fig. 1B). The longitudinal structure of the mandible was described by the tip of the incisor, the anteriormost point of the mandibular bone along the incisor, and the posterior extremity of the condyle. The anterior tip of the pulp cavity and the posterior basis of the enamel layer described internal structures of the mandible. The configurations of landmarks were superimposed using a Procrustes procedure, providing aligned coordinates that were analyzed using a PCA. Geometric differences between the three groups (CB, Guillou 1993 and Guillou 2009) were assessed using a permanova on the PC axes explaining more than $5 \%$ of variance.

The Procrustes superimposition and PCA were performed using geomorph, and the permanova was done using Past 3.

\section{Results}

\section{Measurement error}

The two repeated measurements for the Cologne-Bonn population were not different for lower incisor $(P=0.4571)$ nor for upper incisor shape $(P=0.9997)$. Differences in incisor size between the two measurement sessions were not significant either (lower incisor: $\mathrm{P}=0.535$; upper incisor: $\mathrm{P}=$ $0.925)$. 
The configuration of landmarks and sliding semi-landmarks on the incisors describes only the visible part of the tooth erupted outside the bone. For the lower incisors, the centroid size of this configuration was highly correlated with the size of the mandible bearing it (CS $\sim$ Mandible Area: $R^{2}=$ $0.327, \mathrm{P}<2.2 \mathrm{e}-16$ ) and even more tightly related with the body size (CS Body Weight: $\mathrm{R}^{2}=0.455, \mathrm{P}$ $<2.2 \mathrm{e}-16)$. Guillou mice tended to display slightly larger erupted lower incisors than continental relatives (t-test: $P=0.0004$ ), especially for small-size animals (Fig. $2 A)$. The difference between the two groups (here, continent vs Guillou) was however reduced compared with the size-related variation; the slopes of the relationship with body weight appeared to be slightly different between the two groups (CS BW * group: BW $=45.5 \%$ of the total variance, $\mathrm{P}<2.20 \mathrm{E}-16$; group $=5.1 \%, \mathrm{P}=$ $6.44 \mathrm{E}-07$; interaction $=2.2 \%, \mathrm{P}=0.0008)$.

Allometry appeared as a major factor driving incisor shape variation. Incisor size was correlated with the first axis of the PCA on the aligned coordinates $\left(P C 1,53.7 \%\right.$ of total variance $\sim C S: R^{2}=0.414 ; P<$ 2.2e-16; data not shown). Investigating allometric variations on the aligned coordinates confirmed the importance of size-related shape variation. The difference between Guillou and the continent was however significant and the allometric slope was different between the two groups, but this difference was of reduced importance compared to the overall allometric trend (Fig. 2B) (Procrustes ANOVA: shape $\sim \mathrm{CS} *$ group: $\mathrm{CS}=23.3 \%$ of the total variance, $\mathrm{P}=0.0001$; group $=6.2 \%, \mathrm{P}=0.0001$; interaction $=1.2 \%, P=0.001$ ). With increasing incisor size (and hence increasing age of the animals), the bevel tended to become longer relative to the erupted part of the incisor (Fig. $2 \mathrm{C}$ ).

Despite this important source of within-group variation, continental populations tended to be opposed to Guillou samples along the first axis (CVA1 $=52.0 \%$ ) of a CVA on the aligned coordinates (Fig. 2D), whereas the second axis (CVA2 $=17.7 \%$ ) corresponded to variation among continental samples. Guillou incisors, compared to continental ones, displayed a bevel of more or less the same length, but with a sharper profile, especially at the tip (Fig. 2E; Fig. S2 in Supporting Informations). The differences between groups (localities, and for Guillou the different years of trapping) was a significant (permanova on $\mathrm{PC} 1=53.8 \%, \mathrm{PC2}=28.4 \%$, and $\mathrm{PC}=10.7 \%: \mathrm{P}=0.0001$ ). Associated pairwise tests showed that continental populations were overall well differentiated from Guillou samples (Table 1). In contrast, the different years in Guillou were not or only weakly differentiated; the same pattern occurred among continental localities (Table 1).

\section{Upper incisor 2D size and shape}


Contrary to the lower incisors for which incisor growth seemed more or less constant with increasing body size, the increase in size of the upper incisors tended to progressively reach a plateau (Fig. 3A). Tests were thus performed on log transformed size variables. As for the lower incisor, the centroid size of the upper incisor was highly correlated with the size of the mandible $(\log (\mathrm{CS}) \sim \log ($ Mandible Area): $\left.\mathrm{R}^{2}=0.0505, \mathrm{P}<2.2 \mathrm{e}-16\right)$ and with body size $\left(\log (\mathrm{CS}) \sim \log \left(\right.\right.$ Body Weight): $\mathrm{R}^{2}=0.542, \mathrm{P}<2.2 \mathrm{e}-$ 16). The size of the upper incisor was highly correlated with the size of its lower counterpart $\left(R^{2}=\right.$ $0.361, \mathrm{P}<2.2 \mathrm{e}-16$ ) but increased twice less fast (slope of upper incisor CS lower incisor CS: 0.458 $+/-0.042)$.

Guillou and continental mice displayed upper incisors of similar size (t-test: $P=0.1477)$. This was confirmed in a model including body weight and group as explanatory variables $(\log (C S) \sim \log (B W)+$ group: $\log (\mathrm{BW})=46.9 \%$ of the total variance, $\mathrm{P}<2.20 \mathrm{E}-16$; group $=0.3 \%, \mathrm{P}=0.4220$ ).

Allometry was not a major factor driving upper incisor shape variation. Incisor size was not correlated with the first axis of the PCA on the aligned coordinates $\left(P C 1,60.1 \%\right.$ of total variance $\sim \log (C S): R^{2}=$ $0.0160 ; \mathrm{P}=0.0676$; data not shown). Investigating allometric variations on the aligned coordinates however showed some size-related incisor shape variation, but it was not so marked as the difference between continental and Guillou incisors (Procrustes ANOVA: shape $\sim \log (C S) *$ group: $\log (\mathrm{CS})=3.5 \%$ of the total variance, $\mathrm{P}=0.0378$; group $=10.2 \%, \mathrm{P}=0.0002$; interaction $=2.7 \%, \mathrm{P}=$ 0.0479). With increasing incisor size, the bevel tended to get indented by a small notch (Fig. 3B).

Continental populations tended to be opposed to Guillou samples along the first axis of a CVA on the aligned coordinates (CVA1 $=45.8 \%$ ), but the pattern was less clear than for the lower incisor. Only the oldest samples in Guillou (1993 and and to a lesser extent 2001) markedly diverged along PC1 (Fig. $3 C$ ). The second axis (CVA2 $=22.1 \%$ ) corresponded to variation among continental samples. Guillou incisors, compared to continental ones, displayed a bevel indented by a pronounced notch (Fig. 3D; Fig. S2).

Shape differences between groups (localities, and different years in Guillou) were significant (permanova on $\mathrm{PC1}=60.1 \%, \mathrm{PC2}=16.0 \%, \mathrm{PC}=11.3 \%$, and $\mathrm{PC4}=6.5 \%: \mathrm{P}=0.0001$ ), but associated pairwise tests showed only few highly significant differences (Table 1). The sample from Guillou 1993 was the only one consistently different from all continental populations.

\section{Internal structure of the lower incisors}

Considering cross-sections of the incisors at the basis of the bevel (Fig. 1B), continental and Guillou incisors did not differ in their mean grey value $(G V)(P=0.2041)$ and thus in their average density. 
Similarly, there were not statistically significant differences in maximal GV $(P=0.4068)$. Continental and Guillou incisors differed, however, in the minimal GV observed in this cross-section $(P=0.0261)$ (Fig. 4A). This difference is due to the occurrence in continental incisors of a dark area at the center of the cross-section (Fig. 4A, Fig. S3 in Supporting Informations), corresponding to the pulp cavity which thus extends beyond the contact with the mandibular bone into the erupted part of the incisor.

When considering the whole 3D structure, continental and Guillou mice did not differ in the volume of dentine relative to the mandible volume ( $t$-test: $P=0.0704)$ nor in the mean $G V$ of the dentine $(P=$ 0.2517 ). The same was true for the enamel (relative volume: $P=0.1768$; mean $G V: P=0.3659$ ). This suggests that continental and Guillou mice did not differ substantially in the material properties of the dentine and enamel.

In contrast, the geometry of the dentine and enamel was quite different between continental and Guillou mice (Fig. 4B). Cologne-Bonn and Guillou mice strongly differed along the first axis of the corresponding PCA, explaining more than $80 \%$ of the variance (Fig. 4C). The apex of the pulp cavity was located differently in the different groups: close to the tip of the incisors in continental mice, and much more posteriorly in Guillou mice. Differences between groups were significant (permanova on $P C 1=81.2 \%$ and $P C 2=15.6 \%: P=0.0019)$. Pairwise tests showed no difference between years in Guillou ( $P=0.2617$ ) but significant differences between Cologne-Bonn and the two years in Guillou (CB vs G1993: $P=0.0284 ; C B$ vs $G 2009: P=0.0305)$.

\section{Discussion}

A functionally-relevant difference in lower incisor shape between omnivorous and predator house mice

So far rodent incisors have not received much attention, possibly because of their simple shape. Yet, incisors assure initial food processing and acquisition; as such, they evolved in response to various functions such as digging, cutting up food, piercing and capturing preys (Martin et al., 2016). Compared to omnivorous-granivorous rodents, genera adapted to carnivory tend to display thin, narrow incisors with a straighter curvature improving their functioning for piercing preys (Fabre et al., 2017; Martin et al., 2016; Rowe et al., 2016). Compared to these cases of advanced specialization, incisors of Guillou mice were only moderately modified. Only lower incisors were consistently different from their continental commensal relatives, but they did not differ in incisor depth or curvature. The geometric differences rather involved the bevel angle, sharper in Guillou mice, and 
301

302

303

304

305

306

307

308

309

310

311

312

313

314

315

316

317

318

319

320

321

322

323

324

325

326

327

328

329

330

331

332

hence of adaptive value to stab preys. This limited amount of morphological differentiation may be due to the different evolutionary scales considered: Mice were introduced on the Kerguelen archipelago 150 years ago. Compared to interspecific or even intergeneric evolution, this is a short time span to adapt to local conditions, and even the carnivorous trend of Guillou mice, displaying an increased component of invertebrates and especially earthworms (Le Roux et al., 2002) is less extreme than specialist carnivorous genera (Fabre et al., 2017; Rowe et al., 2016).

\section{Contrasted response of the upper and lower incisors to diet shift}

The upper incisors of Guillou mice did not display a sharper bevel, as their lower counterpart. Rather, they were characterized by a more pronounced notch in the bevel than continental commensal relatives. This difference, however, was only significant for the oldest sample in Guillou, trapped in 1993. This contrasts with the consistent differentiation of the lower incisors between Guillou and continental mice.

The differential response of the lower and upper incisors to the dietary shift is probably related to their different role during occlusion. While gnawing, the rodent anchor its head with the upper incisors while the lowers work as chisels (Ness, 1956), which come into occlusion just behind the upper incisors (Ness, 1956). If food particles do not fully prevent tooth-tooth contact (attrition), the enamel of the lower incisor could thus get in contact with the dentine of the upper incisor, sculpting a notch into it. During this movement, the lower incisor acts as the active pestle in a sort of "pestleand-mortar" system (Müller et al., 2014), submitting it to higher functional demand than the upper incisor. This differential role during occlusion could explain the clearer adaptive response to a diet shift of the lower incisors compared to the upper ones. In contrast, the notch in the upper incisor bevel would be a passive consequence of food comminution on the "mortar" of the system, more marked if attrition is stronger. Based on tooth microwear analyses, mice before rabbit eradication in 1994 displayed a signature of animal-dominated feeders, switching thereafter towards a more generalist diet (Renaud, Gomes Rodrigues, et al., 2015) despite the persistence of animal preys in their diet (Le Roux et al., 2002). Invertebrates, and especially earthworms whose availability decreased over the years in Guillou because of increasing summer drought (Lebouvier et al., 2011), offer little resistance to occlusion, leading to increased tooth-tooth contact while seizing prey. The marked notch in the upper incisor of the oldest Guillou sample, in 1993 and hence before rabbit eradication, probably testify of the abundance of such soft preys in the diet of the mice at that point. 
Incisor response within a complex masticatory apparatus

In rodents, incisors and molars cannot come in occlusion at the same time (Cox \& Jeffery, 2011) and they are involved in different functions, biting at the incisors and chewing at the molars. The jaw is moved by different masticatory muscles, the temporal and masseter muscles being mainly involved during incision and chewing respectively. Depending on the diet, jaw shape is thus submitted to different adaptive pressures to optimize incisor or molar biting. Guillou mice, and more generally Sub-Antarctic mice which all display a shift towards a more predatory behaviour (Copson, 1986; Smith et al., 2002), have been shown to display biomechanical adaptation of jaw morphology to optimize incisor biting (Renaud, Gomes Rodrigues, et al., 2015; Renaud et al., 2018). The sharp lower incisor bevel evidenced by the present study is well adapted to piercing and capturing prey, thus reflecting an adaptation of the incisor tool itself, and not only of the mandible moving it into occlusion. Sharp blade tips are indeed advantageous to faunivorous mammals because they are efficient to produce an initial tear in the tough foodstuff, such as insect cuticle (Popowics \& Fortelius, 1997). The concerted changes of the incisor and jaw hence provides evidences of an integrated adaptation of the masticatory apparatus in response to the diet shift towards a predatory behaviour. Jaw shape was also shown to respond to the environmental changes over years in Guillou, with the pronounced difference between Guillou and continental mice fading out through years (Renaud, Gomes Rodrigues, et al., 2015; Renaud et al., 2013). The jaw shape change through years was interpreted as result of an improved investment in the mineralization of the mandibular bone, derived from the intake of better quality food. The signature observed on the upper incisor is very similar and is likely due to the same resource adjustment despite retaining an overall predatory behaviour.

\section{Incisor shape change through growth and interaction with response to diet}

The size of the incisor increases throughout animal's life (Harari et al., 2005) but incisor growth decelerate with age, due to a decrease in the width of the daily increments (Klevezal \& Shchepotkin, 2012). In the present study, a deceleration of growth was obvious for the upper incisor but not for the lower incisor. This suggests that wear related to occlusion and attrition was not enough to perfectly counterbalance a growth occurring twice as fast as for the upper incisors. Allometric change, as the response to diet, was discrete in the upper incisor, and both involved the sculpting of a notch into the bevel. Being related to attrition during food comminution, this notch seems to increase with age but more markedly in mice relying on soft-food items. Regarding the lower incisor, both allometry and predator diet were associated with a sharper bevel. This shows that the 
sharpening of the bevel occurs while functioning during the animal's life, providing mice with a sharper tool with increasing age. Active attritional behavior may be at least partly responsible for this tapering of the cutting edge of the lower incisor. The more pronounced allometric changes in continental than Guillou mice may be related to two not mutually exclusive factors: the higher prevalence of young individuals in the continental sample, and/or the existence of a higher variability in diet consistency along the life of continental mice.

\section{Incisor continuous growth allowing for a dynamic sculpting as a response to diet}

Incisor growth can be considerably modulated by the use of the incisor itself. The absence of occlusion has been shown to double their rate of eruption in rats. In contrast, soft food causing little abrasion slowed down eruption rate by as much as 35\% (Burn-Murdoch, 1993; Taylor \& Butcher, 1951). Active attrition behavior probably participates to this modulation, contributing to maintain the incisor to an adequate length for occlusion (Taylor \& Butcher, 1951). The process of adjusting eruption rate to a diet change occurs within few days (Ness, 1956; Taylor \& Butcher, 1951). Furthermore, difference in diet consistency were reported to cause differences in the bevel angle that mimic those observed between continental mice, mostly relying on grains, and Guillou mice, largely relying on invertebrate prey. Hard food particles fracture the cutting edge of the incisor, that is sharpened again by attrition of the incisors against each other, but this leads to a greater bevel angle than in unbroken teeth (Taylor \& Butcher, 1951). Such pronounced abrasion requires increased eruption so that the two processes counterbalance for an efficient occlusion.

Continuous growth of the incisors is achieved by a population of stem cells located at the cervical end of the incisor (Sharpe, 2016). From these stem cell population, ameloblasts differentiate that generate enamel in a centripetal direction towards the dentine; whereas odontoblasts, located at the external border of the pulp cavity, generate the dentine in a centrifugal direction towards the enamel. Stem cells are even present at the apex of the pulp cavity, being able to produce restorative dentine in case of exposure of the pulp due to abrasion (Pang et al., 2016). Increased eruption rate, however, is not associated with an increased deposition of dentine and enamel, nor with a displacement of the base of the incisor (Ness, 1956). As a consequence of a decreased quantity of dentine and enamel material per unit of erupted tooth, tooth walls are thinner and the pulp cavity is wider in rabbits experiencing accelerated incisor growth (Ness, 1956). Such a change in the dynamics of eruption was traced here by the differences in internal structure of the lower incisors between continental and Guillou mice. Continental mice, for which incisor eruption rate should be higher to match a higher abrasion, displayed a pulp cavity going much further anteriorly than in Guillou mice. 
In contrast, the pulp cavity hardly reached beyond the zone of molar insertion in Guillou mice. Even the place where mineralized enamel could be detected tended to be located more posteriorly than in continental mice. This can be interpreted as the consequence of more time for depositing enamel and dentine material in the slower growing Guillou incisors. All changes observed between continental and Guillou incisors are thus compatible with a purely plastic response allowed by the modulation of incisor continuous growth. More profound geometric changes, involving incisor depth and curvature were not observed in Guillou mice. The incisor enamel of rodents is usually ironenriched, leading to a harder enamel allowing to sustain important wear. This enamel-hardening is lost in some specialized carnivorous rodents (Rowe et al., 2016). There is no evidence for such a trend in Guillou mice, since mean enamel density appeared to be similar than in continental mice. Changes in such traits would involve the selection of heritable characters, requiring a longer time to evolve in order to lead to specialized phenotypes as those observed in carnivorous taxa (Fabre et al., 2017; Rowe et al., 2016). The incisors of Guillou mice may thus exemplify the adaptive potential of plastic changes to face environmental challenges at an ecological time-scale (Ghalambor et al., 2007).

\section{Conclusion}

Consistent differences in the lower incisor bevel have been shown between continental mice, generally relying on hard food stuffs such as grain, and Guillou mice, that switched their diet towards an increased predatory component. According to functional expectations, the bevel of predatory mice displays a sharper cutting edge allowing for an improved perforation of prey. This bevel shape characteristic of Guillou mice may be largely, if not entirely, the product of a plastic modulation of incisor growth, with a balance between active attritional behavior tapering the cutting edge of the lower incisor, and decreased eruption rate modulated to match decreased abrasion. Such a role of plasticity in tooth geometry and dynamics is largely underestimated, because teeth are usually not prone to plastic variations. Being ever-growing, rodent incisors can however vary in response to environmental differences within the time span of an animal's life, and even over few days. The dynamic sharpening of the bevel would thus constitute another case of tooth sculpting, described so far for particular molar morphology able to perform equally well when unworn and worn, and thus adapted for safeguarding against dental senescence (Pampush et al., 2016).

Investigating the internal structure of the incisor showed that such change in eruption dynamics lead to profound differences in the pulp cavity and even on the place where enamel and dentine mineralized. Because increased eruption rate is not associated with increased rate of enamel and dentine deposition, the whole structure of mineralization is changed, being shifted towards the tip of 
432 the incisor. Such internal signature enables to make a link between evolutionary and behavioral

433 aspects and developmental studies on the mouse incisor (Pang et al., 2016; Sharpe, 2016) and may

434 open the way to investigate eco-evo-devo dynamics of incisor adaptation based on material available 435 in collections.

436

437 Acknowledgements

438 We thank Renaud Lebrun (ISEM, Montpellier) for his contribution in managing CT scans, produced 439 within the technical facilities of the MRI platform and of the labEx CeMEB. We also warmly thank the 440 horse stable Les Peupliers (Balan) for their authorization and support during the trapping, and Jean441 Louis Chapuis for his initiation and long-lasting participation to the IPEV program on Guillou. The 442 manuscript benefited from stimulating discussions within the GDR 'Phenotypic Plasticity' and from 443 constructive comments from two anonymous reviewers. This study was supported by the French 444 Polar Institute (IPEV programme 136) and by the CNRS (Zone Atelier de Recherches sur 445 I'Environnement Antarctique et Subantarctique). 
Adams, C. D., \& Otarola-Castillo, E. (2013). Geomorph: An r package for the collection and analysis of geometric morphometric shape data. Methods in Ecology and Evolution, 4, 393-399.

Burn-Murdoch, R. A. (1993). The effect of the consistency of the diet on eruption rates and lengths of incisor teeth in rats. Archives of Oral Biology, 38, 699-706.

Chapuis, J.-L., Frenot, Y., \& Lebouvier, M. (2004). Recovery of native plant communities after eradication of rabbits from the subantarctic kerguelen islands, and influence of climate change. Biological Conservation, 117, 167-179.

Chapuis, J.-L., Le Roux, V., Asseline, J., \& Kerleau, F. (2001). Eradication of rabbits (oryctolagus cuniculus) by poisoning on three islands of the subantarctic kerguelen archipelago. Wildlife Research, 28, 323-331.

Copson, G. R. (1986). The diet of the introduced rodents mus musculus I. And rattus rattus I. On subantarctic macquarie island. Australia Wildlife Research, 13, 441-445.

Cox, P. G., \& Jeffery, N. (2011). Reviewing the morphology of the jaw-closing musculature in squirrels, rats, and guinea pigs with contrast-enhanced microct. The Anatomical Record, 294, 915-928.

Evans, A. R., Wilson, G. P., Fortelius, M., \& Jernvall, J. (2007). High-level similarity of dentitions in carnivorans and rodents. Nature, 445, 78-81.

Fabre, P.-H., Hautier, L., Dimitrov, D., \& Douzery, E. J. P. (2012). A glimpse on the pattern of rodent diversification: A phylogenetic approach. BMC Evolutionary Biology, 12, 88.

Fabre, P.-H., Herrel, A., Fitriana, Y., Meslin, L., \& Hautier, L. (2017). Masticatory muscle architecture in a water-rat from australasian (murinae, hydromys) and its implication for the evolution of carnivory in rodents. Journal of Anatomy, 231, 380-397.

Ghalambor, C. K., McKay, J. M., Carroll, S. P., \& Reznick, D. N. (2007). Adaptive versus non-adaptive phenotypic plasticity and the potential for contemporary adaptation in new environments. Functional Ecology, 21, 394-407.

Hammer, Ø., Harper, D. A. T., \& Ryan, P. D. (2001). Past: Paleontological statistics software package for education and data analysis. Palaeontological Electronica, 4, 1-9.

Harari, D., Hermolin, G., \& Harari, O. (2005). The effect of age on morphology and eruption of the lower incisors in mature rats. Archives of Oral Biology, 50, 953-958.

Hardouin, E., Chapuis, J.-L., Stevens, M. I., van Vuuren, J. B., Quillfeldt, P., Scavetta, R. J., et al. (2010). House mouse colonization patterns on the sub-antarctic kerguelen archipelago suggest singular primary invasions and resilience against re-invasion. BMC Evolutionary Biology, 10, 325.

Jernvall, J., Hunter, J. P., \& Fortelius, M. (1996). Molar tooth diversity, disparity, and ecology in cenozoic ungulate radiations. Science, 274, 1489-1492.

Kidder, J. H. (1876). The natural history of the kerguelen island. The American Naturalist, 10, 481-484.

Klevezal, G. A., \& Shchepotkin, D. V. (2012). Incisor growth rate in rodents and the record of the entire annual cycle in the incisors of marmota baibacina centralis. Biology Bulletin, 39, 684691.

Landry, S. O. (1970). The rodents as omnivores. The Quaterly Review of Biology, 45, 351-372.

Laparie, M., Lebouvier, M., Lalouette, L., \& Renault, D. (2010). Variations of morphometric traits in populations of an invasive carabid predator (merizodus soledadinus) within a sub-antarctic island. Biological Invasions, 12, 3405-3417.

Le Roux, V., Chapuis, J.-L., Frenot, Y., \& Vernon, P. (2002). Diet of the house mouse (mus musculus) on guillou island, kerguelen archipelago, subantarctic. Polar Biology, 25, 49-57.

Lebouvier, M., Laparie, M., Hullé, M., Marais, A., Cozic, Y., Lalouette, L., et al. (2011). The significance of the sub-antarctic kerguelen islands for the assessment of the vulnerability of native communities to climate change, alien insect invasions and plant viruses. Biological Invasions, 13, 1195-1208.

Lowe, S., Browne, M., Boudjelas, S., \& De Poorter, M. 2000. 100 of the world's worst invasive alien species. A selection from the global invasive species database. pp. 1-12): The Invasive Species 
Specialist Group (ISSG) a specialist group of the Species Survival Commission (SSC) of the World Conservation Union (IUCN).

Martin, S. A., Alhajeri, B. H., \& Steppan, S. J. (2016). Dietary adaptations in the teeth of murine rodents (muridae): A test of biomechanical predictions. Biological Journal of the Linnean Society, 119, 766-784.

Meredith, A. L., Prebble, J. L., \& Shaw, D. J. (2015). Impact of diet on incisor growth and attrition and the development of dental disease in pet rabbits. Journal of Small Animal Practice, 56, 377382.

Millien-Parra, V. (2000). Species differentiation among muroid rodents on the basis of their lower incisor size and shape: Ecological and taxonomical implications. Mammalia, 64, 221-239.

Müller, J., Clauss, M., Codron, D., Schulz, E., Hummel, J., Fortelius, M., et al. (2014). Growth and wear of incisor and cheek teeth in domestic rabbits (oryctogalus cuniculus) fed diets of different abrasiveness. Journal of Experimental Zoology, Part A, 321A, 283-298.

Ness, A. R. (1956). The response of the rabbit mandibular incisor to experimental shortening and to the prevention of its eruption. Proceedings of the Royal Society of London, Biological Sciences (serie B), 146, 129-154.

Pampush, J. D., Spradley, J. P., Morse, P. E., Harrington, A. R., Allen, K. L., Boyer, D. M., et al. (2016). Wear and its effects on dental topography measures in howling monkeys (alouatta palliata).

Pang, Y. W. Y., Feng, J., Daltoe, F., Fatscher, R., Gentleman, E., Gentleman, M. M., et al. (2016). Perivascular stem cells at the tip of mouse incisors regulate tissue regeneration. Journal of Bone and Mineral Research, 31, 514-523.

Popowics, T. E., \& Fortelius, M. (1997). On the cutting edge: Tooth blade sharpness in herbivorous and faunivorous mammals. Annales Zoologici Fennici, 34, 73-88.

Renaud, S., Dufour, A.-B., Hardouin, E. A., Ledevin, R., \& Auffray, J.-C. (2015). Once upon multivariate analyses: When they tell several stories about biological evolution. PLOS ONE, 10, e0132801.

Renaud, S., Gomes Rodrigues, H., Ledevin, R., Pisanu, B., Chapuis, J.-L., \& Hardouin, E. A. (2015). Fast morphological response of house mice to anthropogenic disturbances on a sub-antarctic island. Biological Journal of the Linnean Society, 114, 513-526.

Renaud, S., Hardouin, E. A., Pisanu, B., \& Chapuis, J.-L. (2013). Invasive house mice facing a changing environment on the sub-antarctic guillou island (kerguelen archipelago). Journal of Evolutionary Biology, 26, 612-624.

Renaud, S., Hardouin, E. A., Quéré, J.-P., \& Chevret, P. (2017). Morphometric variations at an ecological scale: Seasonal and local variations in feral and commensal house mice. Mammalian Biology, 87, 1-12.

Renaud, S., Ledevin, R., Pisanu, B., Chapuis, J.-L., Quillfeldt, P., \& Hardouin, E. A. (2018). Divergent in shape and convergent in function: Adaptive evolution of the mandible in sub-antarctic mice. Evolution, 72, 878-892.

Rohlf, F. J., \& Slice, D. (1990). Extensions of the procrustes method for the optimal superimposition of landmarks. Systematic Zoology, 39, 40-59.

Rowe, K. C., Achmadi, A. S., \& Esselstyn, J. A. (2016). Repeated evolution of carnivory among indoaustralian rodents. Evolution, 70, 653-665.

Samuels, J. X., \& Van Valkenburgh, B. (2009). Craniodental adaptations for digging in extinct burrowing beavers. Journal of Vertebrate Paleontology, 29, 254-268.

Schlager, S. 2017. Morpho and rvcg - shape analysis in \{r\}. In G. Zheng, S. Li \& G. Szekely (Eds) Statistical shape and deformation analysis. pp. 217-256): Academic Press.

Sharpe, P. T. (2016). Dental mesenchymal stem cells. Development, 143, 2273-2280.

Smith, V. R., Avenant, N. L., \& Chown, S. L. (2002). The diet and impact of house mice on a subantarctic island. Polar Biology, 25, 703-715.

Steppan, S. J., \& Schenk, J. J. (2017). Muroid rodent phylogenetics: 900 -species tree reveals increasing diversification rates. PLOS ONE, 12, e0183070.

Taylor, A. C., \& Butcher, E. O. (1951). The regulation of eruption rate in the incisor teeth of the white rat. Journal of Experimental Zoology, 117, 165-188. 
550 van Aarde, R. J., \& Jackson, T. P. (2007). Food, reproduction and survival in mice on sub-antarctic marion island. Polar Biology, 30, 503-511.

552

553

554 
557

558

559

560

561

562

563

564

565

566

567

568

569

570

571

572

573

574

575

576

577

578

579

580

581

582

583

584

Figure legends

Figure 1. Data set for the quantification of the incisors shape and internal structure. (A) Example of right upper and lower incisor on the mouse head, with the set of 2D landmarks and semi-landmarks used for the 2D shape analysis in the yellow inserts. (B) Lingual profile of a right hemi-mandible, based on $\mu \mathrm{CT}$-scans. The surface of the mandible including teeth, of the dentine and of the enamel were segmented using constant grey value (GV) thresholds. The transparency allows visualizing the location of the pulp cavity and of the enamel layer. Arrowheads point to the five landmarks used to describe the internal structure of the incisor relative to the mandible: tip of the incisor, anteriormost point of the bone along the incisor, posterior extremity of the condyle (in grey); apex of the pulp cavity (in purple) and basis of the enamel layer (in blue).

Figure 2. Lower incisor size and shape variation. A. Incisor centroid size vs. body weight. B. Allometric incisor shape variation, depicted as the variation of the allometric regression score vs. incisor centroid size. Dotted lines correspond to the linear trends in the two groups (continent and Guillou). C. Allometric shape difference between the smallest and the largest incisor (no magnification). D. Differentiation in incisor shape between the different mouse populations, along the first two axes of a Canonical Variate Analysis on the aligned coordinates. Guillou populations: light green, G1993; green, G2001; light blue, G2008; dark blue: G2009. Continental populations: red: Balan; pink: Tourch; violet: Gardouch; yellow: CB. E. Mean shape difference between continental and Guillou incisors (magnification: $\mathrm{x} 2$ ).

Figure 3. Upper incisor size and shape variation. A. Incisor centroid size vs. body weight. B. Allometric shape difference between the smallest and the largest incisor (no magnification). C. Differentiation in incisor shape between the different mouse populations, along the first two axes of a Canonical Variate Analysis on the aligned coordinates. Guillou populations: light green, G1993; green, G2001; light blue, G2008; dark blue: G2009. Continental populations: red: Balan; pink: Tourch; violet: Gardouch; yellow: CB. D. Mean shape difference between continental and Guillou incisors (magnification: $\times 2$ ). 
586

587

588

589

590

591

592

593

594

595

596

597

598

599

600

601

602

603

604

605

606

607

608

609

610

611

612

613

614

Figure 4. Internal structure of the lower incisor in a subset of continental (brown dots) and Guillou mice (green and blue dots), based on $\mu$ CT-scan data. A. Minimal grey value of a cross-section of the lower incisor between the bevel and the insertion in the mandibular bone. B. Example of a continental and a Guillou mandible, with mandible, dentine and enamel segmented with constant grey value thresholds. Arrowheads point to the five landmarks describing the internal structure of the incisor relative to the mandible. Grey arrowheads: tip of the incisor, anteriormost point of the bone along the incisor and coronoid posterior extremity. Purple arrowhead: apex of the pulp cavity; blue arrowhead: enamel basis. The pulp cavity extends much more anteriorly in continental mice. $\mathrm{C}$. Plot of the PCA based on the aligned coordinates of the five landmarks. Brown: Cologne-Bonn (CB), in blue: Guillou 1993 and in darkblue: Guillou 2009. D. Visualization of the deformation along PC1. Right: configuration at the minimum value along PC1; left, configuration at the maximum value along PC1.

\section{List of Supporting Informations}

Table S1. Area, country, locality and code (abbreviation) for the different sampled populations. NLowInc: number of lower incisors measured in 2D. NUpplnc: number of upper incisors measured in 2D. N3D: number of lower incisors included in the 3D analysis. Collection: source and place of locations of the skulls. MPI Plön: Max Plank Institut of Evolutionary Biology, Plön, Germany; CBGP: Centre de Biologie et Gestion des Populations, Baillarguet, France; LBBE: Laboratoire de Biométrie et Biologie Evolutive, France.

Figure S1. Map of the localities considered in this study.

Figure S2. Consensus shape of the upper and lower incisors for continental and Guillou mice.

Figure S3. Cross-section of lower incisor between the basis of the bevel and the insertion of the bone, for Cologne-Bonn (brown, upper row), Guillou 1993 (green, mid row) and Guillou 2009 (blue, lower row) mice. Right, location of the cross-section on a mandible (bone in violet, dentine in pink, enamel in orange).

Supplementary data 1. Raw data for the lower incisor geometric morphometrics.

Supplementary data 2. Raw data for the upper incisor geometric morphometrics. 
615 Tables

616 Table 1. Incisor shape differentiation between geographic groups.

\begin{tabular}{|c|c|c|c|c|c|c|c|c|c|c|c|}
\hline Lower incisor & Locality & Group & $\mathrm{N}$ & Balan & $\mathrm{CB}$ & Gardouch & Tourch & G1993 & G2001 & G2008 & G2009 \\
\hline & Balan & Continent & 14 & - & & & & & & & \\
\hline & $\mathrm{CB}$ & Continent & 14 & 0.0083 & - & & & & & & \\
\hline & Gardouch & Continent & 68 & 0.0277 & 0.0261 & - & & & & & \\
\hline & Tourch & Continent & 88 & 0.1111 & 0.0020 & 0.0190 & - & & & & \\
\hline & G1993 & Guillou & 22 & 0.0002 & 0.0804 & 0.0002 & 0.0001 & - & & & \\
\hline & G2001 & Guillou & 19 & 0.0007 & 0.0001 & 0.0002 & 0.0004 & 0.0001 & - & & \\
\hline & G2008 & Guillou & 20 & 0.0005 & 0.0001 & 0.0001 & 0.0009 & 0.0001 & 0.7118 & - & \\
\hline & G2009 & Guillou & 22 & 0.0065 & 0.0007 & 0.0026 & 0.0006 & 0.0186 & 0.0105 & 0.0427 & - \\
\hline \multirow[t]{9}{*}{ Upper incisor } & & & & Balan & $\mathrm{CB}$ & Gardouch & Tourch & G1993 & G2001 & G2008 & G2009 \\
\hline & Balan & Continent & 9 & - & & & & & & & \\
\hline & $\mathrm{CB}$ & Continent & 14 & 0.0389 & - & & & & & & \\
\hline & Gardouch & Continent & 59 & 0.0008 & 0.3080 & - & & & & & \\
\hline & Tourch & Continent & 59 & 0.0847 & 0.0645 & 0.0001 & - & & & & \\
\hline & G1993 & Guillou & 16 & 0.0026 & 0.0010 & 0.0001 & 0.0001 & - & & & \\
\hline & G2001 & Guillou & 16 & 0.0181 & 0.0618 & 0.0174 & 0.0014 & 0.0801 & - & & \\
\hline & G2008 & Guillou & 16 & 0.0021 & 0.0932 & 0.0897 & 0.0001 & 0.0113 & 0.2503 & - & \\
\hline & G2009 & Guillou & 20 & 0.0033 & 0.4857 & 0.0515 & 0.0108 & 0.0011 & 0.0200 & 0.0323 & \\
\hline
\end{tabular}

617

618 Upper panel: lower incisor; shape variables: first three PC axes. Lower panel: upper incisor; shape

619 variables: first four PC axes. N: sample size. Probabilities of pairwise permanova are provided, based 620 on 9999 permutations. In italics: $\mathrm{P}<0.01$; in bold $\mathrm{P}<0.001$.

621

622

623 
Figure 1. Data set for the quantification of the incisors shape and internal structure. (A) Example of right upper and lower incisor on the mouse head, with the set of 2D landmarks and semi-landmarks used for the 2D shape analysis in the yellow inserts. (B) Lingual profile of a right hemi-mandible, based on $\mu \mathrm{CT}$-scans. The surface of the mandible including teeth, of the dentine and of the enamel were segmented using constant grey value (GV) thresholds. The transparency allows visualizing the location of the pulp cavity and of the enamel layer. Arrowheads point to the five landmarks used to describe the internal structure of the incisor relative to the mandible: tip of the incisor, anteriormost point of the bone along the incisor, posterior extremity of the condyle (in grey); apex of the pulp cavity (in purple) and basis of the enamel layer (in blue).
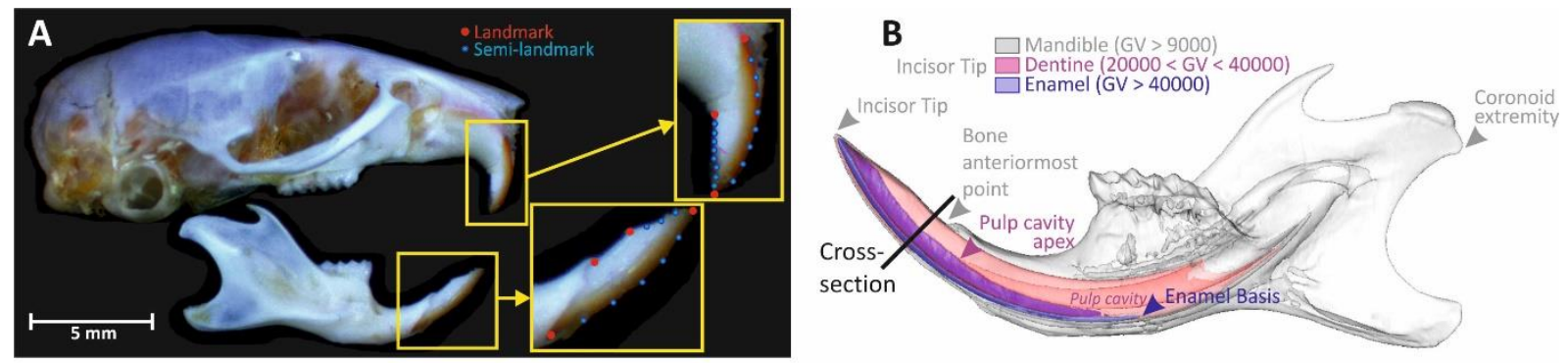
Figure 2. Lower incisor size and shape variation. A. Incisor centroid size vs. body weight. B. Allometric incisor shape variation, depicted as the variation of the allometric regression score vs. incisor centroid size. Dotted lines correspond to the linear trends in the two groups (continent and Guillou). C. Allometric shape difference between the smallest and the largest incisor (no magnification). D. Differentiation in incisor shape between the different mouse populations, along the first two axes of a Canonical Variate Analysis on the aligned coordinates. Guillou populations: light green, G1993; green, G2001; light blue, G2008; dark blue: G2009. Continental populations: red: Balan; pink: Tourch; violet: Gardouch; yellow: CB. E. Mean shape difference between continental and Guillou incisors (magnification: $x 2$ ).
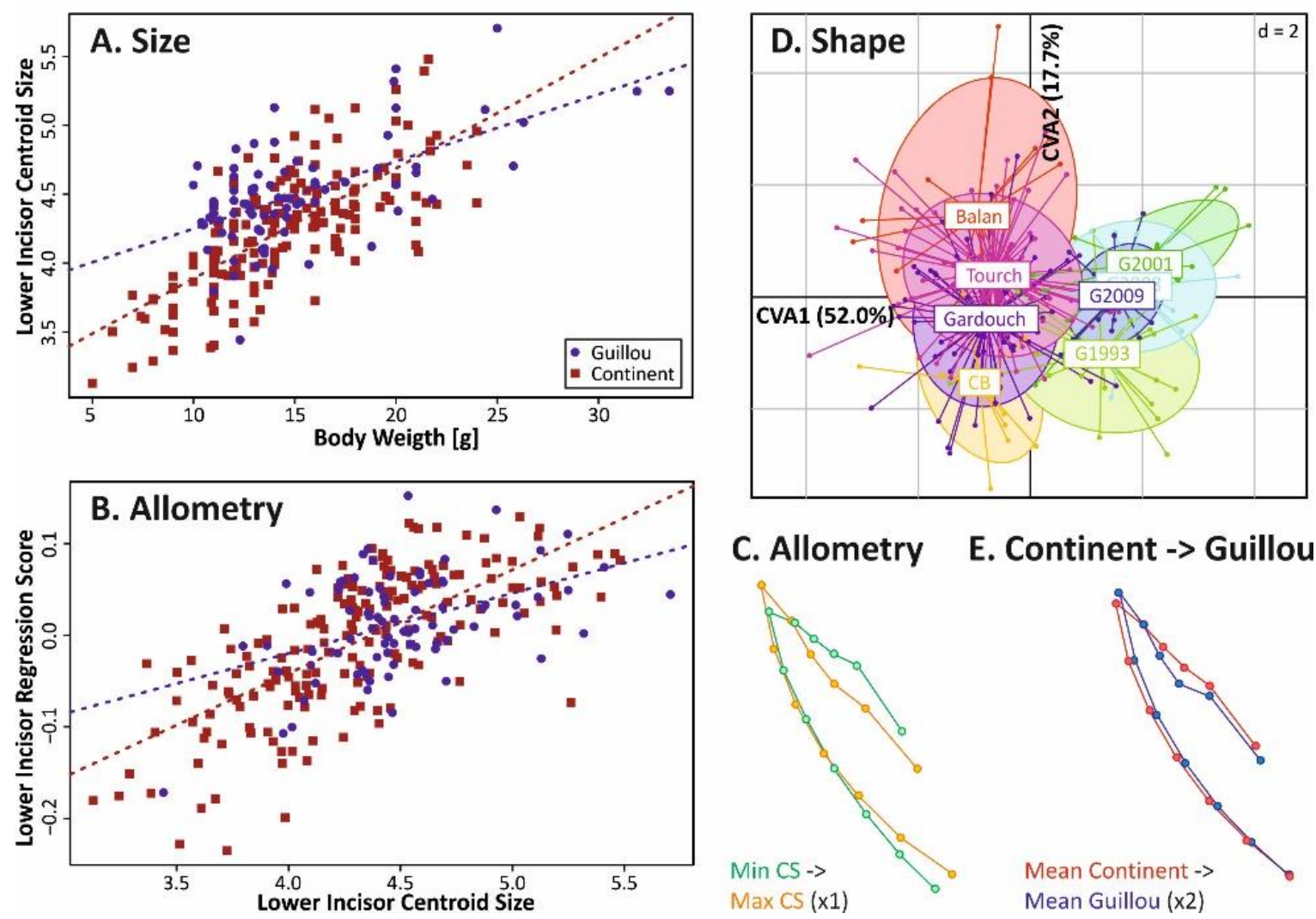

\section{Allometry E. Continent -> Guillou}
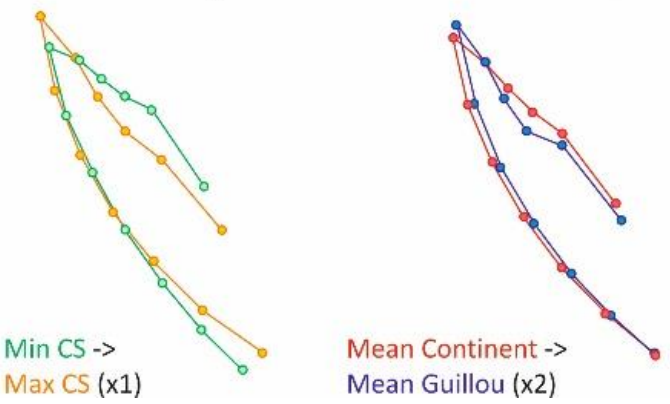
Figure 3. Upper incisor size and shape variation. A. Incisor centroid size vs. body weight. B. Allometric shape difference between the smallest and the largest incisor (no magnification). C. Differentiation in incisor shape between the different mouse populations, along the first two axes of a Canonical Variate Analysis on the aligned coordinates. Guillou populations: light green, G1993; green, G2001; light blue, G2008; dark blue: G2009. Continental populations: red: Balan; pink: Tourch; violet: Gardouch; yellow: CB. D. Mean shape difference between continental and Guillou incisors (magnification: $\mathrm{x} 2$ ).
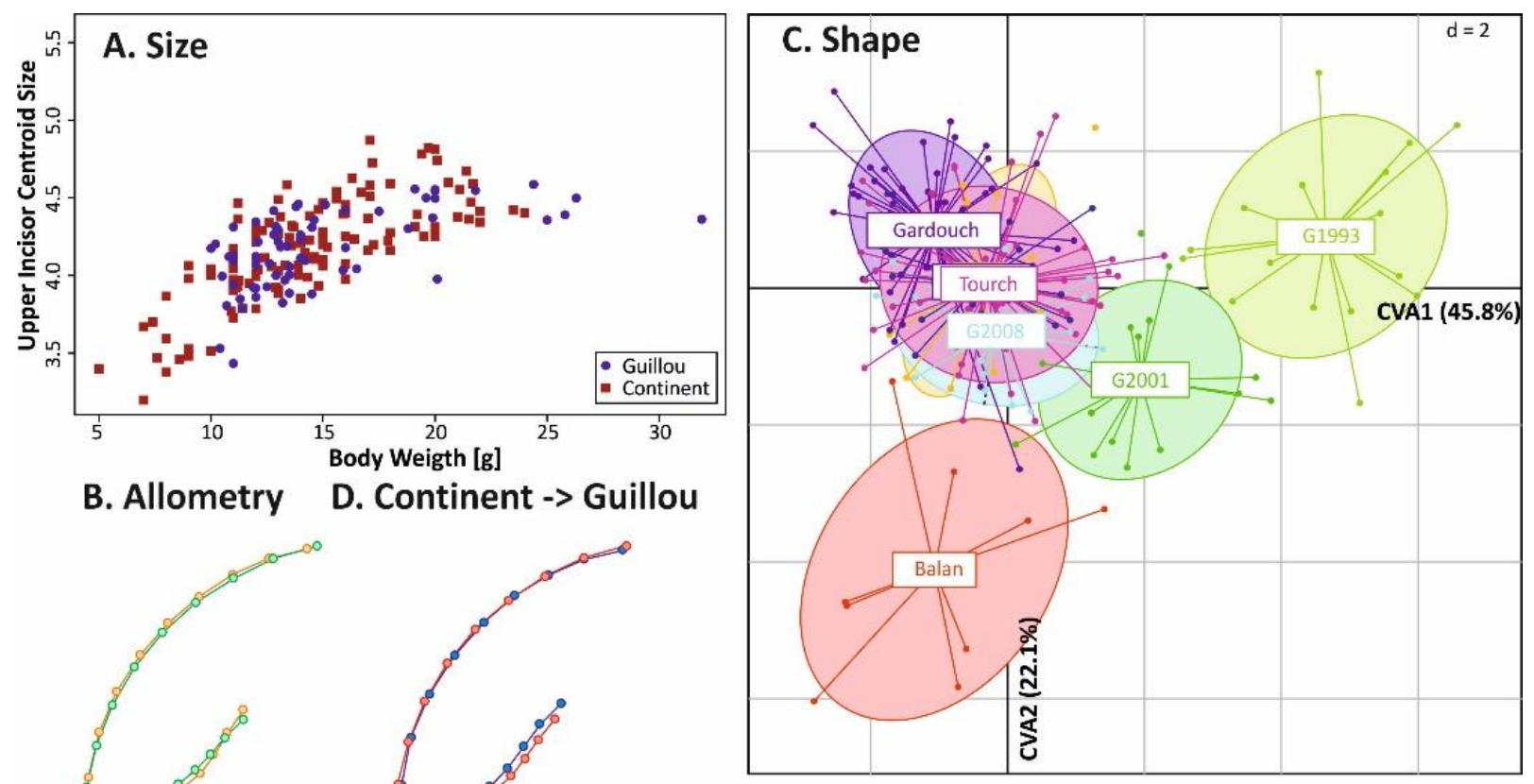

B. Allometry
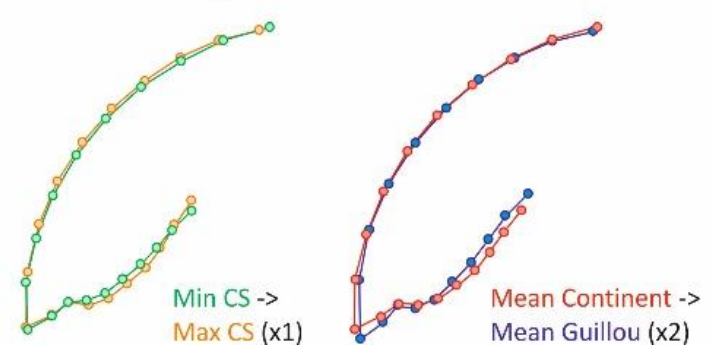
Figure 4. Internal structure of the lower incisor in a subset of continental (brown dots) and Guillou mice (green and blue dots), based on $\mu \mathrm{CT}$-scan data. A. Minimal grey value of a cross-section of the lower incisor between the bevel and the insertion in the mandibular bone. B. Example of a continental and a Guillou mandible, with mandible, dentine and enamel segmented with constant grey value thresholds. Arrowheads point to the five landmarks describing the internal structure of the incisor relative to the mandible. Grey arrowheads: tip of the incisor, anteriormost point of the bone along the incisor and coronoid posterior extremity. Purple arrowhead: apex of the pulp cavity; blue arrowhead: enamel basis. The pulp cavity extends much more anteriorly in continental mice. $\mathrm{C}$. Plot of the PCA based on the aligned coordinates of the five landmarks. Brown: Cologne-Bonn (CB), in blue: Guillou 1993 and in darkblue: Guillou 2009. D. Visualization of the deformation along PC1. Right: configuration at the minimum value along PC1; left, configuration at the maximum value along PC1.

\section{A. Cross-section}
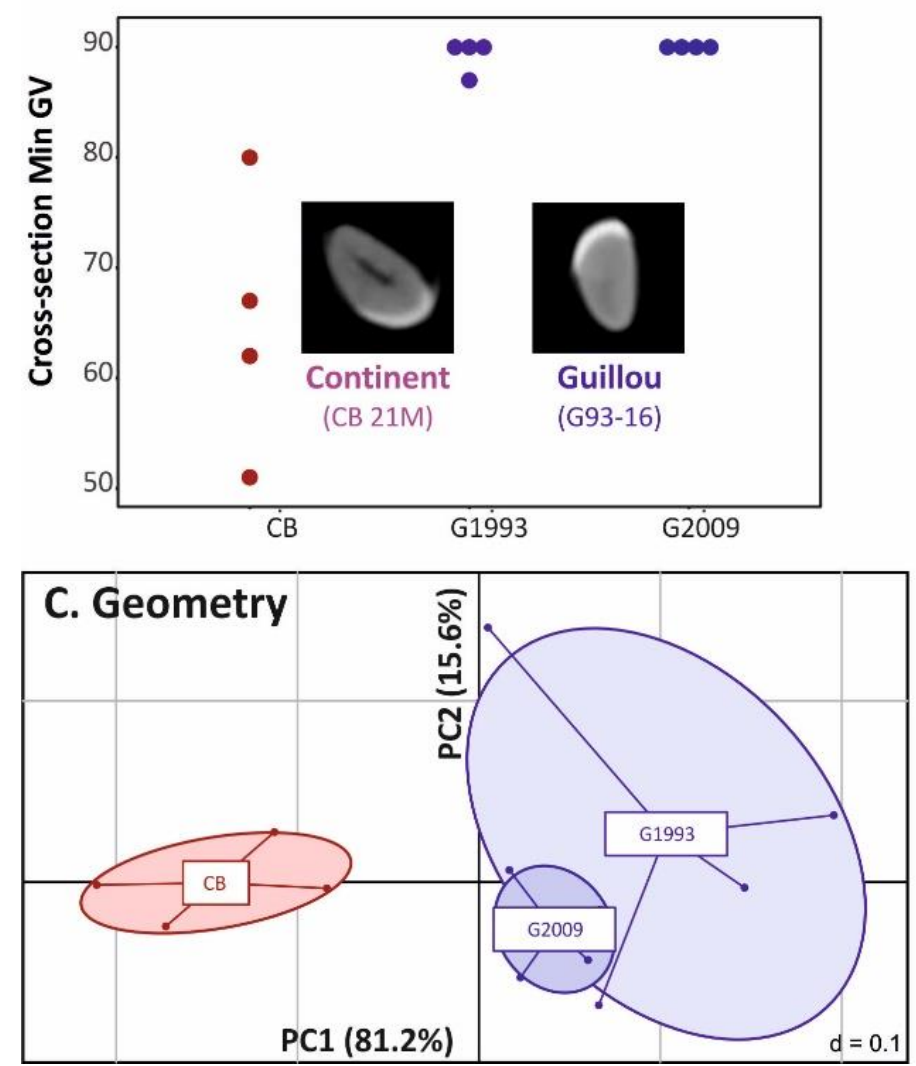

B.

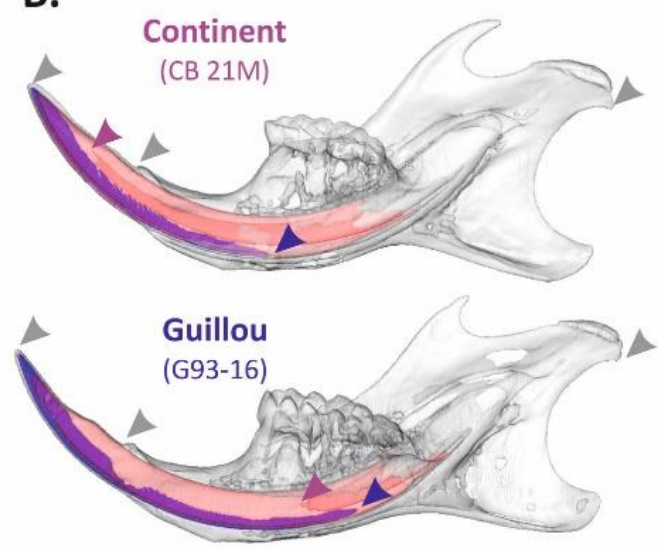

D. Geometric changes along PC1

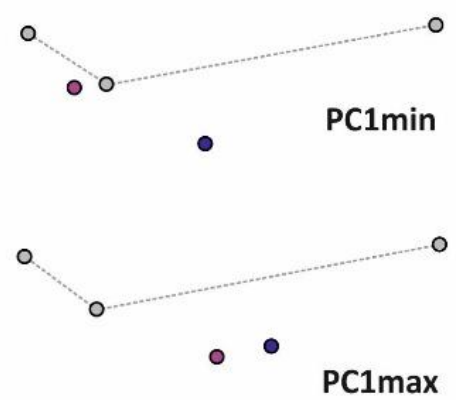




\section{Supplementary Figures}

Supplementary Figure 1. Map of the localities considered in this study.

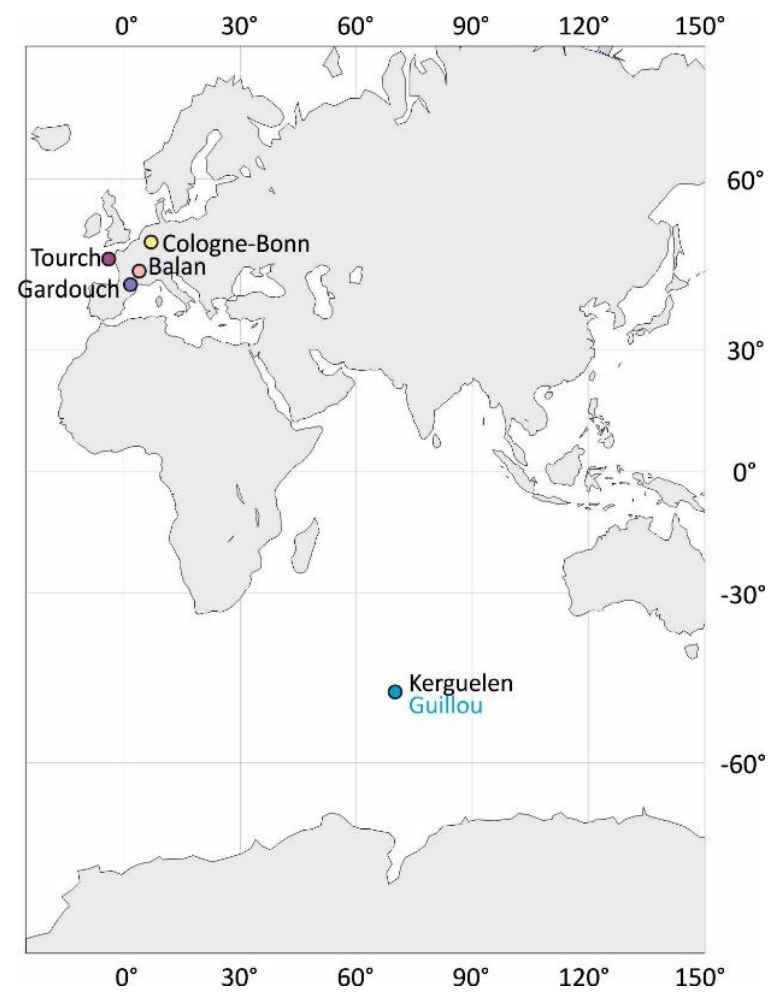

Supplementary Figure 2. Consensus shape of the upper and lower incisors for continental and Guillou mice.

Mean shape continent Mean shape Guillou
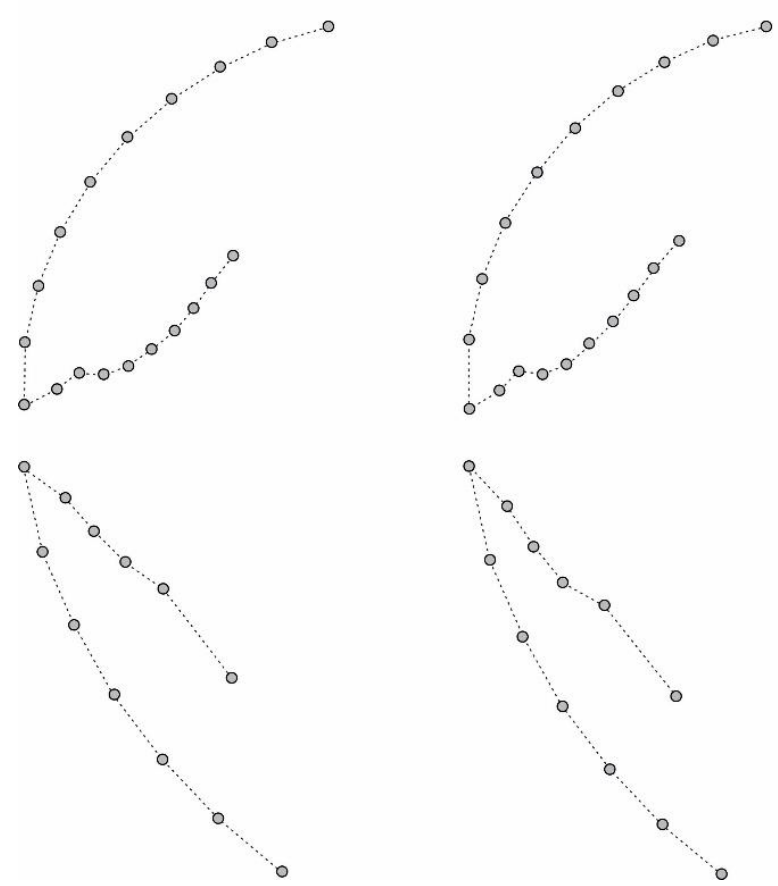
Supplementary Figure 3. Cross-section of lower incisor between the basis of the bevel and the insertion of the bone, for Cologne-Bonn (brown, upper row), Guillou 1993 (green, mid row) and Guillou 2009 (blue, lower row) mice. Right, location of the cross-section on a mandible (bone in violet, dentine in pink, enamel in orange).

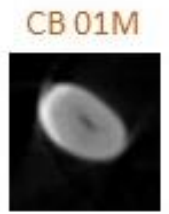

G93-02b

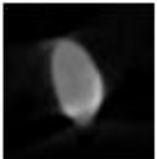

G09-01

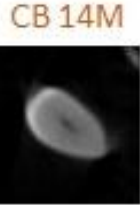

G93-16

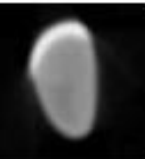

609-03

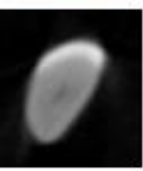

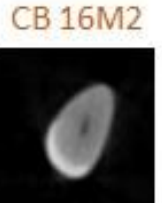

G93-20

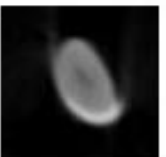

G09-14

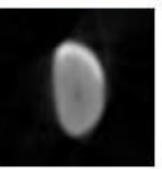

CB 21M

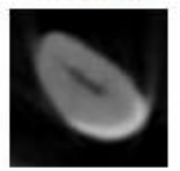

G93-23

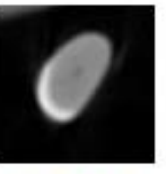

G09-23b

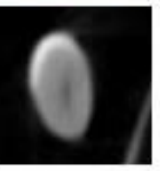

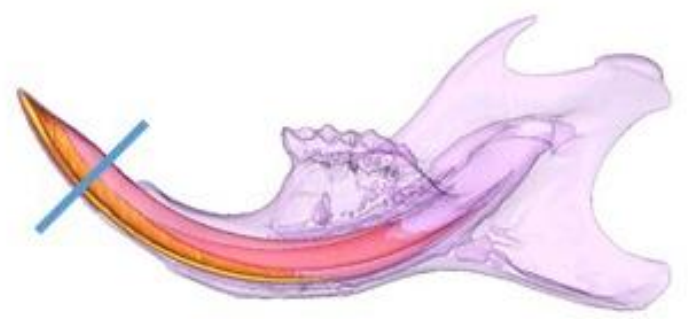

